\title{
INVESTIGATION OF FRICTION STIR WELDING PARAMETERS IN THE STIRRED ZONE FOR A356 AI CAST ALLOY
}

\author{
E. Y. El-Kady ${ }^{*}$, T.S. Mahmoud ${ }^{*}$, M. Nemat-Alla ${ }^{* *}$ and \\ I. M. Hassab-Allah \\ *Mechanical Engineering Department, Shobra Faculty of Engineering, \\ Benha University, Shobra, Egypt \\ **Mechanical Engineering Department, Faculty of Engineering, Assiut \\ University, Assiut 71516, Egypt
}

\section{(Received January 25, 2009 Accepted February 15, 2009)}

\begin{abstract}
In the present investigation, the design of experiments (DOE) approach was used to optimize both the tool rotation and welding speeds for the friction stir welding (FSW) of A356 Al-Si alloy. Experiments were designed using $3^{2}$ factorial design technique. Plates of A356 alloy were welded at tool rotation speeds of 300, 500, and $800 \mathrm{rpm}$, and welding speeds of 12,16, and $20 \mathrm{~mm} / \mathrm{min}$. Models were developed to calculate the size of both $\alpha$-Al grains and Si particulates in the stirred zone (SZ) of welded A356 plates, as functions of both tool rotation and welding speeds and also their combined effect. A comparison was made between measured and calculated data. It has been found that the calculated results were in good agreement with measured data.
\end{abstract}

KEYWORDS: Friction stir welding, design of experiments, Aluminium, Microstructural characteristics.

\section{INTRODUCTION}

Friction stir welding (FSW) is a relatively new solid-state joining technique, developed by The Welding Institute (TWI) of the UK in 1991 [1]. FSW has attracted a considerable attention in industry due to its advantages when compared with the other conventional welding techniques, such as metal inert gas (MIG) and gas tungsten arc welding (GTAW) [1-4]. The principal advantages of FSW over conventional welding techniques are high joining speed, reduced need for human skill, low distortion, improved metallurgical properties, high joint strength and excellent mechanical properties. It has been reported that FSW was successfully applied to joining of various types of $\mathrm{Al}$ [3,4], $\mathrm{Mg}$ [5,6], $\mathrm{Ni}$ [7], Ti [8] and $\mathrm{Cu}$ [9] alloys. Moreover, FSW was also successfully used for welding dissimilar alloys $[10,11]$ as well as composite materials $[12,13]$.

In FSW, a non-consumable rotating tool with specially designed pin and shoulder is inserted into the abutting edges of sheets or plates to be joined and traversed along the line of joint interface to form the weld. During FSW, a plasticized zone is formed due to the frictional heat generated between the tool and the workpiece. When the rotating tool is traversed along the join line, the pin forces the plasticized 
material to flow in the direction of tool rotation assisting in the deposition of the material behind the pin where it cools and consolidates [1].

For FSW of aluminum alloys, the weld zone has three distinct regions: the stirred zone (SZ), heat-affected zone (HAZ), and thermo-mechanically affected zone (TMAZ) [1, 3, and 4]. The SZ experiences a combination of thermal cycle and extensive plastic deformation resulting in an extra-fine microstructure. The HAZ experiences a thermal cycle, but does not undergo any plastic deformation. The TMAZ experiences both heat and deformation during FSW, but the deformation is not allowing recrystallization to occur in this zone due to insufficient strain.

It has been reported that for FSW, both tool rotation speed $(\omega)$ and welding (traverse) speed (v) exhibit a significant effect on the microstructural and mechanical characteristics of the formed zones [1,14-17]. It was noted that the grain size in SZ can be reduced by decreasing the tool rotation speed at a constant tool traverse speed or decreasing the ratio of $\omega / v[1]$. Generally, increasing the tool rotation speed generate higher temperature in the welded zone because of higher friction heating and plastic deformation result in more intense stirring and mixing of material. Tomotake et al. [16] showed that for $5083 \mathrm{Al}$ alloy, the hardness of the SZ increases with the decrease in friction heat flow because the grain size in the SZ decreases with the fiction heat flow. Lim et al. [17] showed that both strength and elongation of 6061Al-T651 decreased with decreasing welding speed and increasing rotation speed.

The quality of the FSW joints and also the efficiency of such process depend upon many parameters such as the nature of the welded material, welding tool shape (shape of pin and shoulder), tool rotation and welding speeds, applied pressure, and the tilt angle. Therefore, the optimization of such parameters is very important to achieve sound FSW joints. In the present investigation, the design of experiments (DOE) technique was adopted, in order to optimize the FSW parameters. DOE is a powerful technique that used for exploring new processes, gaining increased knowledge of the existing processes and optimizing these processes for achieving high performance [18]. Nowadays, this technique is widely used in field of materials science for optimization many metallurgical processes $[19,20]$. The aim of this work is to use DOE technique to optimize both the tool rotation and welding speeds for the FSW of A356 Al-Si alloy. The effect of these parameters on the microstructural characteristics of the $\mathrm{SZ}$ was studied using DOE technique.

\section{DESIGN OF EXPERIMENTS AND EXPERIMENTAL PROCEDURES}

\subsection{Materials}

The material used in the present investigation is A356 Al-Si cast alloy. The chemical composition of the alloy is listed in Table 1.

Table 1. Chemical composition of A356 cast Al-Si alloy.

\begin{tabular}{|c|c|c|c|c|c|c|c|}
\hline $\mathrm{Si}$ & $\mathrm{Fe}$ & $\mathrm{Cu}$ & $\mathrm{Mn}$ & $\mathrm{Mg}$ & $\mathrm{Zn}$ & $\mathrm{Ti}$ & $\mathrm{Al}$ \\
\hline 6.72 & 0.25 & 0.11 & 0.002 & 0.27 & 0.04 & 0.043 & Bal. \\
\hline
\end{tabular}




\subsection{Design of Experiments}

The $3^{2}$ factorial experimental design technique was adopted to collect the necessary data about the effect of both tool rotation and welding speeds on the grain size of the $\alpha-\mathrm{Al}$ phase $\left(\mathrm{D}_{\alpha-\mathrm{Al}}\right)$ as well as the size of the Si particulates $\left(\mathrm{D}_{\mathrm{Si}}\right)$ at the SZ [15]. $3^{2}$ means that there are 2 factors under investigation (i.e. tool rotation speed, $\omega$ and welding speed, $v$ ) and it is planned that each factor is studied at 3 levels representing the minimum, mean and maximum levels of the factor. In the present investigation the minimum, mean and maximum levels of the factors are denoted by $-1,0$, and +1 , respectively. Table 2 lists the experiment number and the level of each factor in the experiment. Table 3 shows the FSW factors and their values.

In $3^{2}$ factorial experimental design technique, the regression model relating the response $y\left(\mathrm{D}_{\alpha-\mathrm{Al}}\right.$ or $\left.\mathrm{D}_{\mathrm{Si}}\right)$ to the factors $\omega$ (tool rotation speed) and $v$ (welding speed) can be represented by:

$$
D=\beta_{0}+\beta_{1} \omega+\beta_{2} v+\beta_{12} \omega v+\beta_{11} \omega_{1}^{2}+\beta_{22} v_{2}^{2}+\varepsilon
$$

where $\beta_{1}, \beta_{2} \ldots$ are the regression coefficients and $\beta_{0}$ is the average response in a factorial experiment. The term " $\varepsilon$ " is the random error component which is approximately normally and independently distributed with mean zero and constant variance $\sigma^{2}$. The regression coefficient $\beta_{12}$ corresponds to the interaction between the process parameters $\omega$ and $v$. The previous regression model can be used to predict the sizes of the primary $\alpha-\mathrm{Al}$ grains and $\mathrm{Si}$ particulates in the SZ over the experimental region. The design of experiments calculations was implemented using Minitab commercial statistical software.

Table 2. The experiment number and the level of each factor in each experiment.

\begin{tabular}{|c|c|c|}
\hline \multirow{2}{*}{ Experiment No. } & \multicolumn{2}{|c|}{ Level } \\
\cline { 2 - 3 } & Factor $\omega$ & Factor $v$ \\
\hline 1 & -1 & 0 \\
2 & -1 & +1 \\
3 & +1 & -1 \\
4 & 0 & 0 \\
5 & +1 & 0 \\
6 & 0 & +1 \\
7 & 0 & -1 \\
8 & +1 & +1 \\
9 & -1 & -1 \\
\hline
\end{tabular}

Table 3. The FSW parameters and their levels

\begin{tabular}{|c|c|c|c|c|}
\hline \multirow{2}{*}{$\begin{array}{c}\text { Factor } \\
\text { Symbol }\end{array}$} & \multirow{2}{*}{ Factor Description } & \multicolumn{3}{|c|}{ Level value } \\
\cline { 3 - 5 } & & Min. (-1) & Mean (0) & Max. (+1) \\
\hline$\omega$ & Tool rotation speed (rpm) & 300 & 500 & 800 \\
$v$ & Welding speed (mm/min) & 12 & 16 & 20 \\
\hline
\end{tabular}




\subsection{The FSW Procedures}

Plates from A356 alloy having $6 \mathrm{~mm}$ thickness, $200 \mathrm{~mm}$ length and $50 \mathrm{~mm}$ width were machined from the small ingots and heat treated at $\mathrm{T} 6$ condition. The alloy was solution treated at $540{ }^{\circ} \mathrm{C}$ for 3 hours followed by quenching in cold water. After cooling they were artificially aged at $160{ }^{\circ} \mathrm{C}$ for 6 hours. After heat treatment the plates were welded at tool rotation and welding speeds shown in Tables 2 and 3 by using a vertical milling machine. Figure 1 shows a schematic illustration of the FSW carried out in the present investigation. A tool with a shoulder of $25 \mathrm{~mm}$ diameter and a simple type cylindrical pin of $6 \mathrm{~mm}$ diameter and $5.5 \mathrm{~mm}$ length was used. Figure 2 shows a photograph for the FSW tool. The tool was made from $\mathrm{H} 13$ tool steel having the chemical composition shown in Table 4. The tool tilt angle for all welds was maintained constant at $3^{\circ}$ and the applied pressure was held constant by keeping constant depth of the tool immersed in the A356 plate. The fixation of the plates was carried out using a specially design fixture shown in Fig. 3.

3. Table 4. Chemical composition of H13 steel.

\begin{tabular}{|c|c|c|c|c|c|c|}
\hline $\mathrm{C}$ & $\mathrm{Mn}$ & $\mathrm{Cr}$ & $\mathrm{V}$ & $\mathrm{Mo}$ & $\mathrm{Si}$ & $\mathrm{Fe}$ \\
\hline 0.39 & 0.40 & 5.2 & 0.95 & 1.4 & 1.10 & Bal. \\
\hline
\end{tabular}

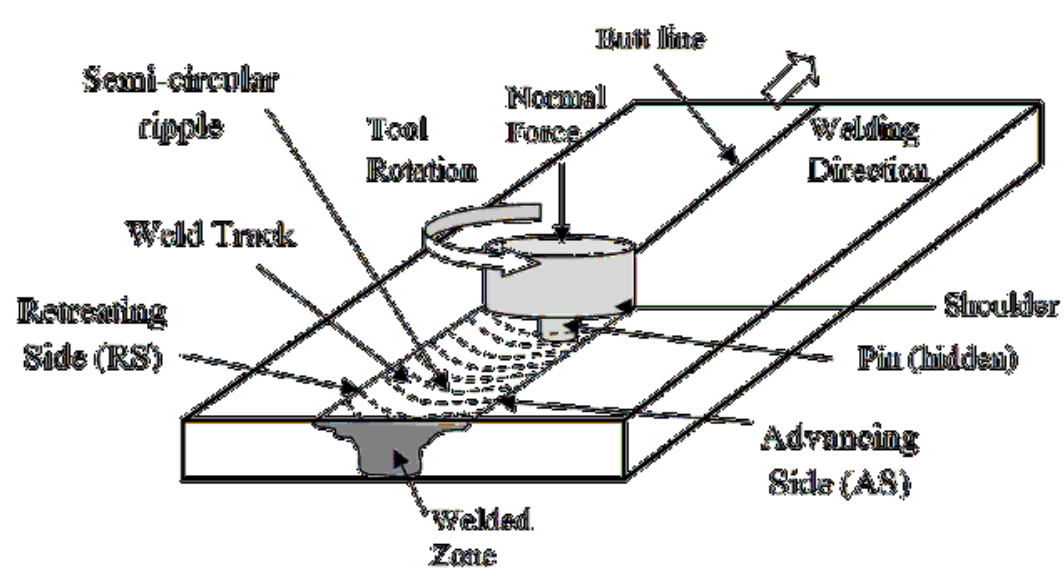

Fig. 1. A schematic description of FSW process.

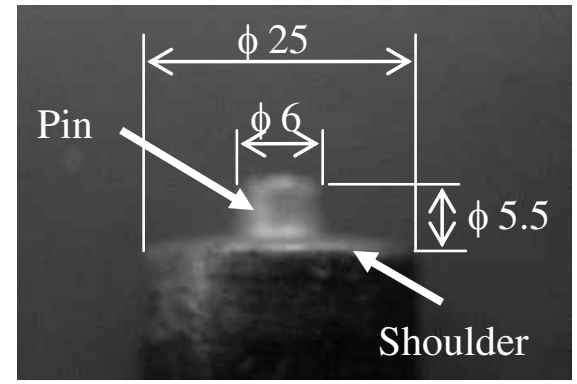

Fig. 2. H13 FSW tool.

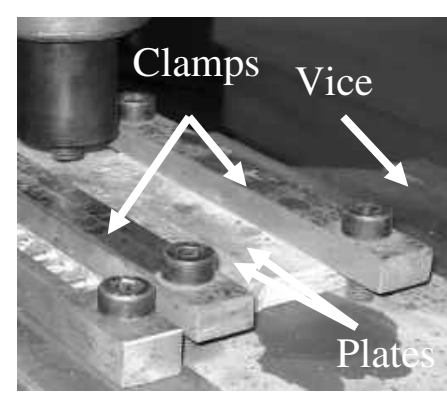

Fig. 3. Plates fixation during FSW. 


\subsection{Metallographic Examination}

Specimens from the FSW plates were cross-sectioned perpendicular to the welding direction and then grounded, polished and examined without etching using standard metallographic techniques. Macro- and Microstructural features were characterized by optical microscopy (OM) and scanning electron microscopy (SEM). Grain sizes of both primary $\alpha$-Al grains and Si particulates in the SZ as well as the base metal (BM) were measured by image analyzing techniques.

\subsection{Appearance of the Weld}

Figure 4 shows the formation of the burrs at the surface of two joints welded at constant welding speed of $20 \mathrm{~mm} / \mathrm{min}$ and 300 and 800 tool rotation speeds, respectively. It has been found that both tool rotation and welding speeds have a great influence on the surface quality. The surfaces of all FSW joints are characterized by presence of semicircular streaks at the contact surface between the shoulder and the plates. However, the size and shape of the streaks is determined by both the tool rotation and traverse speeds. Increasing rotation and/or reducing the welding speeds tend to reduce the surface quality and the semicircular streaks can be observed clearly. This can be explained by the overheating of the welded alloy which causing local melting of the back side of the weld [1]. Another observation of the weld surfaces is the formation of wavy burrs specially with increasing the rotation speed. The difference between the sizes of the burrs is clearly seen when comparing Fig. 4a with Fig. $4 \mathrm{~b}$ in which the burr size formed at 800 r.p.m is much larger than those formed at 300 r.p.m.

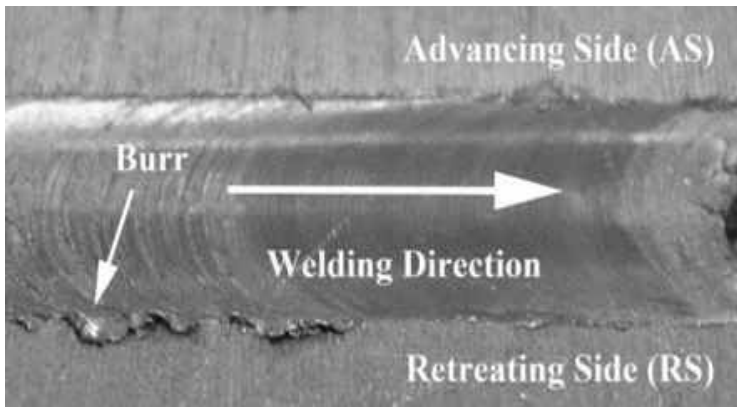

(a)

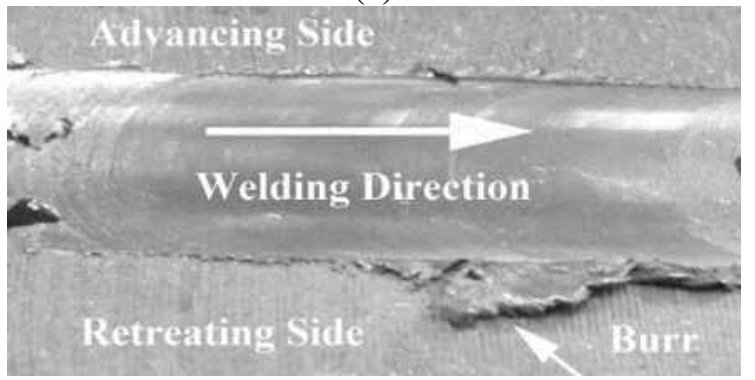

$10 \mathrm{~mm}$

(b)

Fig. 4. The shape of wavy burrs formed at welding speed of $20 \mathrm{~mm} / \mathrm{min}$ and tool rotation speeds of (a) 300 r.p.m. and (b) 800 r.p.m. 


\subsection{Macro- and Micro-structural Observations of the Weldments}

\subsubsection{Macrostructural observations}

Figure 5 show macrographs of FSW joints obtained at several tool rotation and welding speeds at the minimum and maximum levels. It is clear from Fig. 5 that, except for the specimen in Fig. 5b, the welded zones (WZ) contains groove-like cavities at the retreating side (RS) as shown by arrow. However, the size of the cavities was found to be depends on both tool rotation and welding speeds. At constant welding speed, increasing the tool rotation speed from 300 to $800 \mathrm{rpm}$ has significantly improved the soundness of welded by reducing the size of the cavity as shown in Fig. 5b and 5d. In contrast, it has been found that, at constant tool rotation speed, increasing the welding speed increases the size of the cavities. It can be noticed from Fig. 5, that at constant tool rotation speed, increasing the welding speed from 12 $\mathrm{mm} / \mathrm{min}$ to $20 \mathrm{~mm} / \mathrm{min}$ increases the size of the cavity. The most sound joint was observed for the FSW joint that welded at $12 \mathrm{~mm} / \mathrm{min}$ and tool rotation speeds of 800 rpm (i.e. at the maximum level of factor $(\omega)$ and the minimum level of factor $(v)$ ).

A cavity or groove-like defect found in the welded joints is attributed to the insufficient heat input during the FSW. The insufficient heat input defects were found to be form at the lower rotation speed and the higher welding speed [21]. Higher tool rotation speeds generate higher temperature due to higher friction heating and plastic deformation result in more intense stirring and mixing of material. This assists in eliminating the cavities and produces more sound joints.

\subsubsection{Microstructural observations}

An example of the microstructure of the cross-section of FSW joints is illustrated in Fig.6. The micrograph shown in Fig. 6 is for a specimen welded at welding speed of $12 \mathrm{~mm} / \mathrm{min}$ and tool rotation speed of $800 \mathrm{rpm}$ at the edge of the WZ and at advancing sides AS of the welded joint. It has been observed that the microstructure of FSW joints consist of three distinct zones; the fine-grained dynamically recrystallized stirred zone (SZ), the thermo-mechanically affected zone (TMAZ), and the heat affected zone (HAZ). At the TMAZ the material was experienced temperature and deformation during FSW. This zone is characterized by a highly deformed structure. The HAZ is the zone that is not affected by the mechanical deformation but only thermally affected by the frictional heat generated by the shoulder and tool pin rotation.

It is clear from Fig. 6 that the structure of the A356 Al alloy base material (BM) consists of primary $\alpha$ phase (white regions) and Al-Si eutectic structure (darker regions). Large needle-like primary Si particulates were found to be distributed along the boundaries of the $\alpha$-Al dendrites, see Fig. 7a. The microstructure of the SZ is completely different from that of the BM. The SZ has much more homogeneous microstructure as compared to the BM. The dendrite structure disappeared and finer $\mathrm{Si}$ particles are dispersed over the whole SZ, see Fig. 7b. The material within the FSW zones experienced intense stirring and mixing which resulted in the breakup of both the coarse acicular Si particles and the dendritic structure which gave a homogeneous distribution of the $\mathrm{Si}$ particles throughout the $\mathrm{Al}$ alloy matrix. Investigation of the microstructure of the welded joints revealed that the TMAZ are formed besides the SZ 
in both the advancing side (AS) and the retreating side (RS). The difference in the microstructure of the TMAZ in both sides is that a sharp transition between the BM and the SZ is observed in the RS. A wider zone of this deformed structure is observed at the AS, which shows a more diffuse transient region.

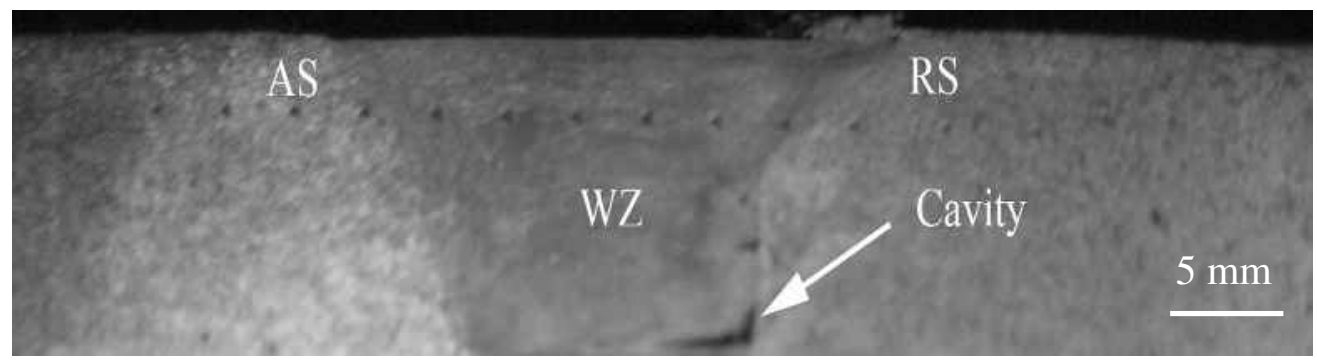

(a) $\omega=300 \mathrm{rpm}, v=12 \mathrm{~mm} / \mathrm{min}$

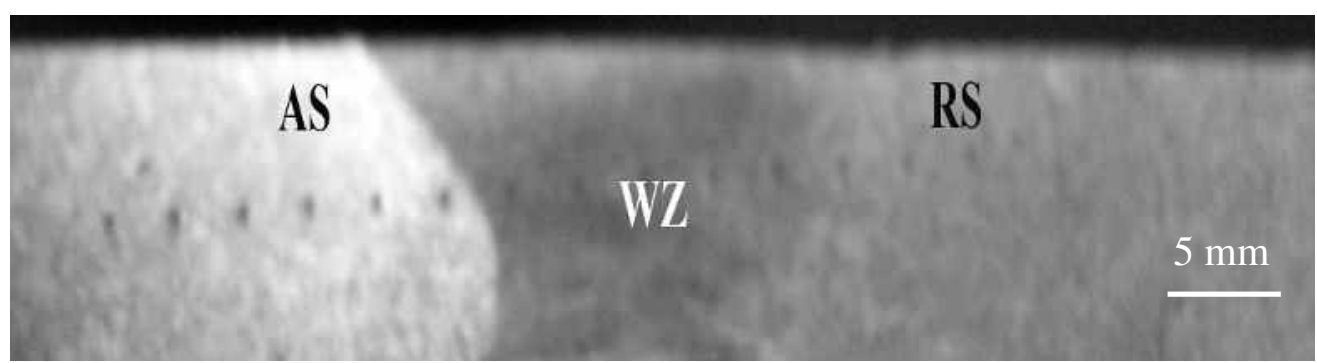

(b) $\omega=800 \mathrm{rpm}, v=12 \mathrm{~mm} / \mathrm{min}$

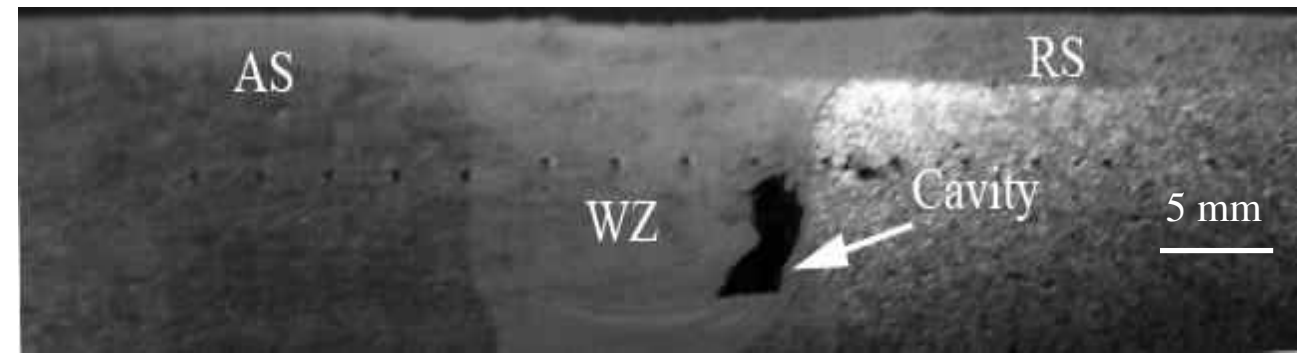

(c) $\omega=300 \mathrm{rpm}, v=20 \mathrm{~mm} / \mathrm{min}$

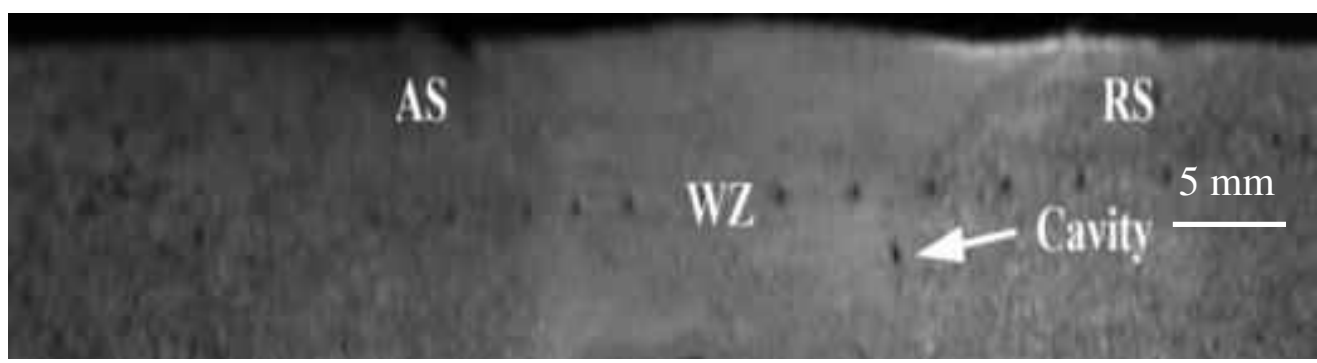

(d) $\omega=800 \mathrm{rpm}, v=20 \mathrm{~mm} / \mathrm{min}$

Fig. 4. Macrographs of FSW joints welded at several tool rotation ( $\omega)$ and welding speeds (v). 


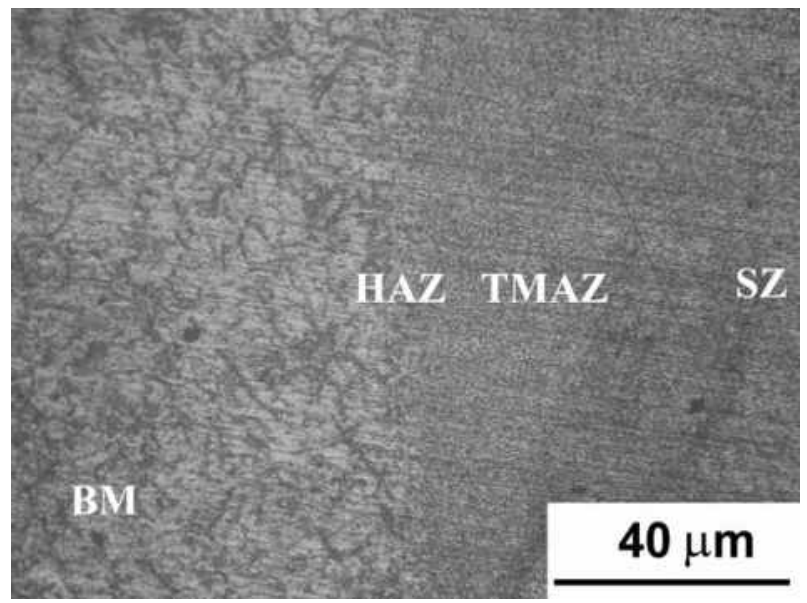

Fig. 6. Microstructure of FSW joint at the advancing side of the WZ edge $(\omega=800 \mathrm{rpm}$ and $v=12 \mathrm{~mm} / \mathrm{min}$ ).

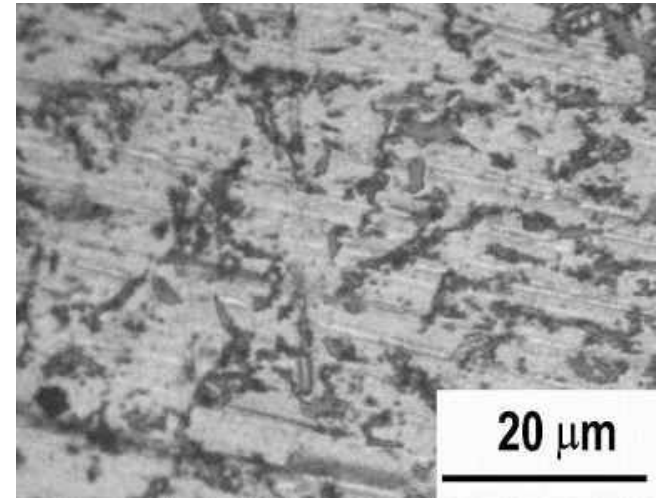

(a)

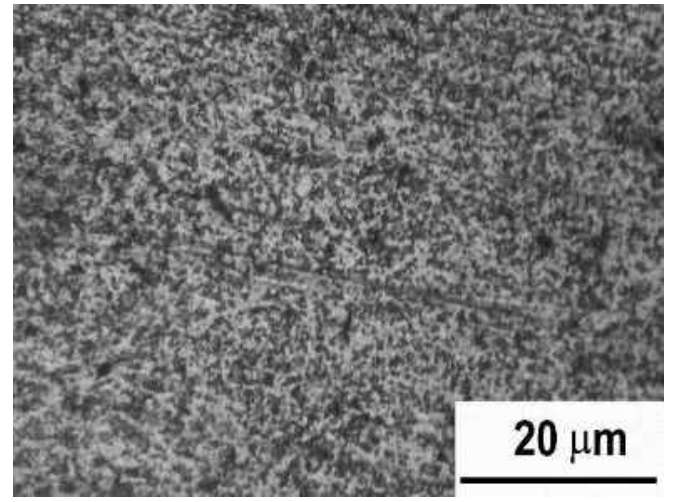

(b)

Fig. 7. Higher magnification of both (a) BM and (b) SZ zones showing the difference in the morphology of Si particles.

\subsubsection{Modelling for $\alpha$-Al grain size.}

Figure 8 shows the variation of $\alpha$-Al grain size, at the center of SZ, with both tool rotation and welding speeds. The points in the figure represent the experimental measurements of grain sizes (observed data), while the shown surface is developed by DOE technique (the predicted values using the fitted model). It is clear from Fig. 8 that the $\alpha$-Al grain size has been reduced by decreasing both tool rotation and welding speeds. Equation 2 represents the regression equation which has been fitted to the data of the $\alpha$-Al grain size. The equation of the fitted model is expressed as:

$$
D_{\alpha-A L}=-7.6573+0.0055 \varpi+0.9313 v-0.000144 \varpi v-6.6667 \times 10^{-7} \varpi^{2}-0.01979 v^{2}
$$


where $D_{\alpha-A l}$ is average size of $\alpha$ - $\mathrm{Al}$ grains in $\mu \mathrm{m}, \omega$ is the tool rotation speed in rpm, and $v$ is the welding speed in $\mathrm{mm} / \mathrm{min}$. The results indicated that the developed model as fitted explains $94.3 \%$ of the variability in the average size of $\alpha$-Al grains.

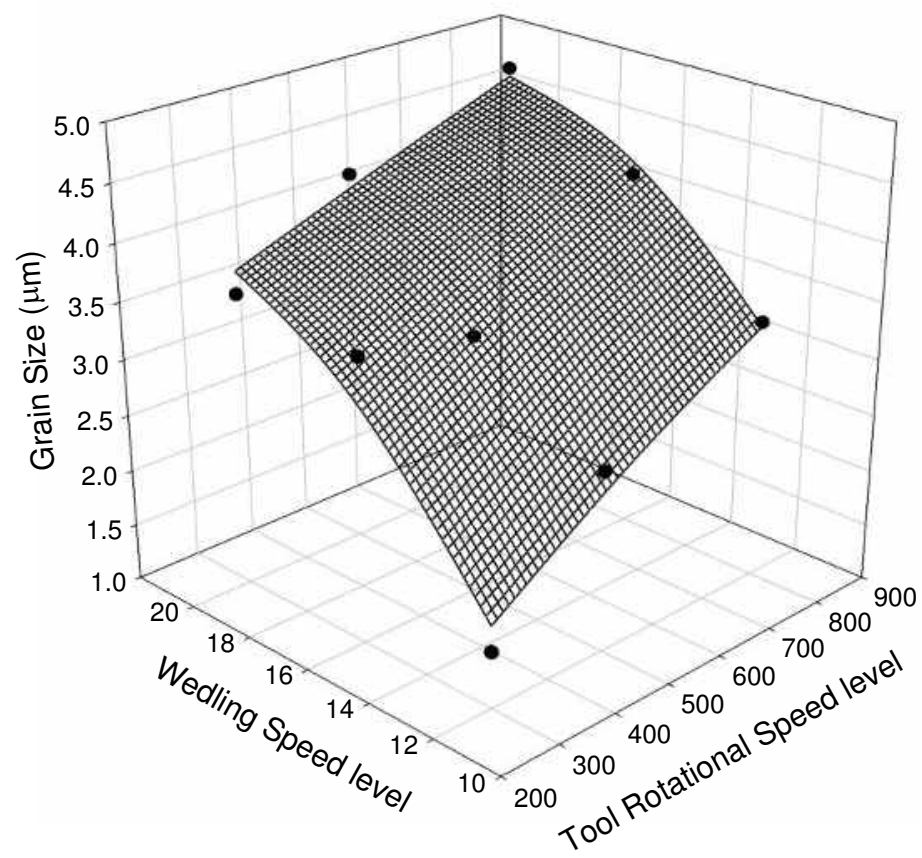

Fig. 8. Variation of $\alpha$-Al grain size with both tool rotation and welding speeds.

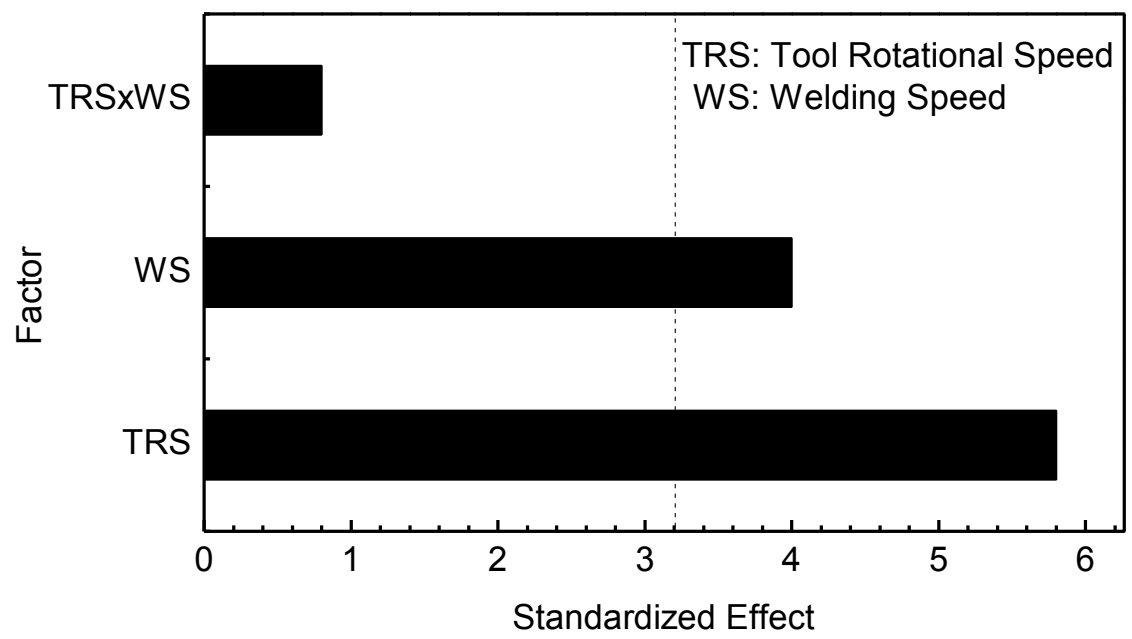

Fig. 9. Standardized Pareto chart for size of $\alpha$-Al grains.

Figure 9 shows the Pareto chart for the effects that investigated in the present study. The Pareto chart is a specialized version of a histogram that ranks the factors 
from most frequent to least frequent. The chart shows that both of tool rotation and welding speeds have the most significant influence on the on the size of $\alpha$-Al grains. The chart shows also that the tool rotation speed has the most significant effect on the size of $\alpha$-Al grains. The welding speeds showed slightly lower significance than the tool rotation speed. The lowest significance is exhibited by the combination of the aforementioned speeds.

\subsubsection{Modelling for the size of Si particulates.}

The variation of Si particulates size, at the center of SZ, with both tool rotation and welding speeds is illustrated in Figure 10. The points in the figure represent the experimental measurements of the average $\mathrm{Si}$ particulates size, while the surface represents the predicted values using the fitted model. It is clear from Fig. 10 that the average size of Si particulates has been increased by increasing both tool rotation and welding speeds. Equation 2 represents the regression equation which has been fitted to the data of the primary Si particulates. The equation of the fitted model is expressed that:

$$
D_{S i}=-4.8772+0.0144 \varpi+0.13815 v-0.001743 \varpi v+1.8889 \times 10^{-5} \varpi^{2}+0.03125 v^{2}
$$

where $D_{s \mathrm{i}}$ is average size of primary Si particulates in $\mu \mathrm{m}, \omega$ is the tool rotation speed in rpm, and $v$ is the welding speed in $\mathrm{mm} / \mathrm{min}$. The results indicated that the developed model as fitted explains $99.2 \%$ of the variability the average size of Si particulates.

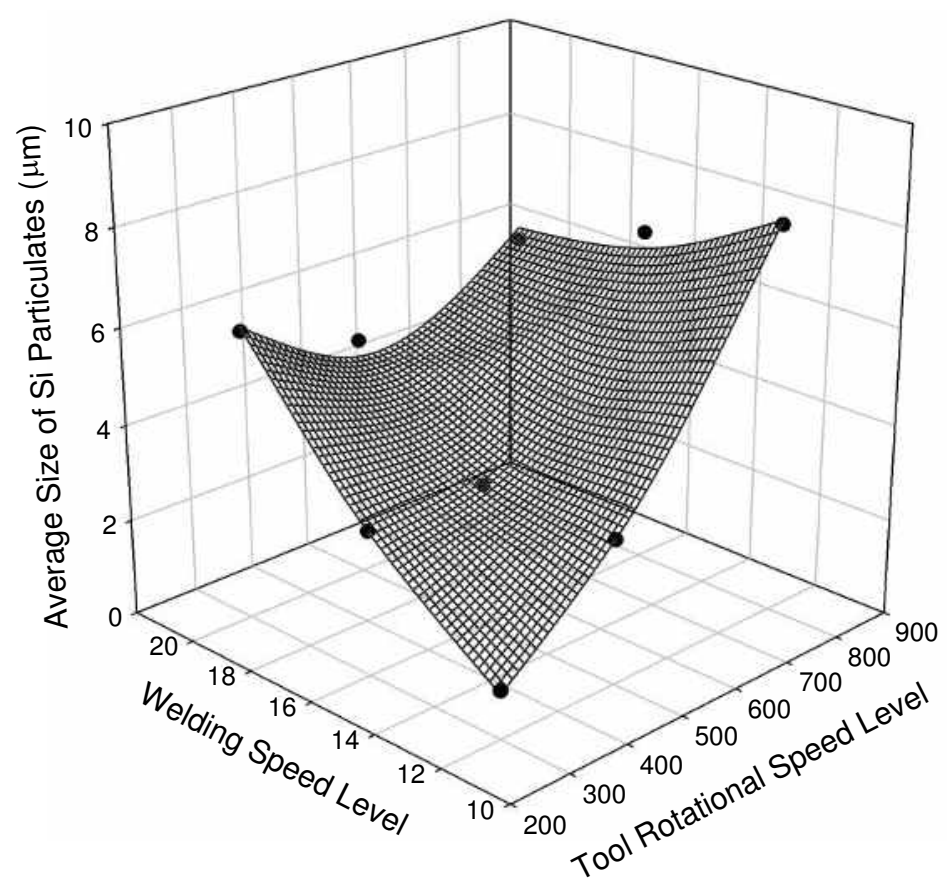

Fig. 10. Variation of Si particulates with both tool rotation and welding speeds. 
Figure 11 shows the influence of the tool rotation and welding speeds and their interaction on the size of Si particulates. It is clear that the tool rotation speed has the most significant influence on the size of $\mathrm{Si}$ particulates, followed by the combination of tool rotation and welding speeds. The welding speed showed the lowest significant effect on the size of Si particulates.

Few investigations were carried out to study the effect of both tool rotation and welding speeds on the microstructural characteristics of FSW cast monolithic Al$\mathrm{Si}$ alloys [15,22], . It is well known that both the morphology (size and shape) of both the $\alpha$-Al grains and Si particulates significantly influence on the mechanical properties of the FSW welded joints. Kim et al. [15] studied the FSW of ADC12 (Al-12\%Si) alloy and showed that the size of the Si particles decreases with increasing welding speed, while it is not significantly affected by the tool rotation speed. In contrast, Mahmoud et al. [22] studied the FSW of A319 alloy and showed that the average size of both of the Si particles and $\alpha$-Al grains increases with increasing both the tool rotation and welding speeds. It seems that the results from the two investigations are in contrast with each other. However, the results obtained in the present work revealed that not only the tool rotation and welding speeds determine the size of Si particles inside the SZ, but also the combined effect of both these speeds has a considerable influence.

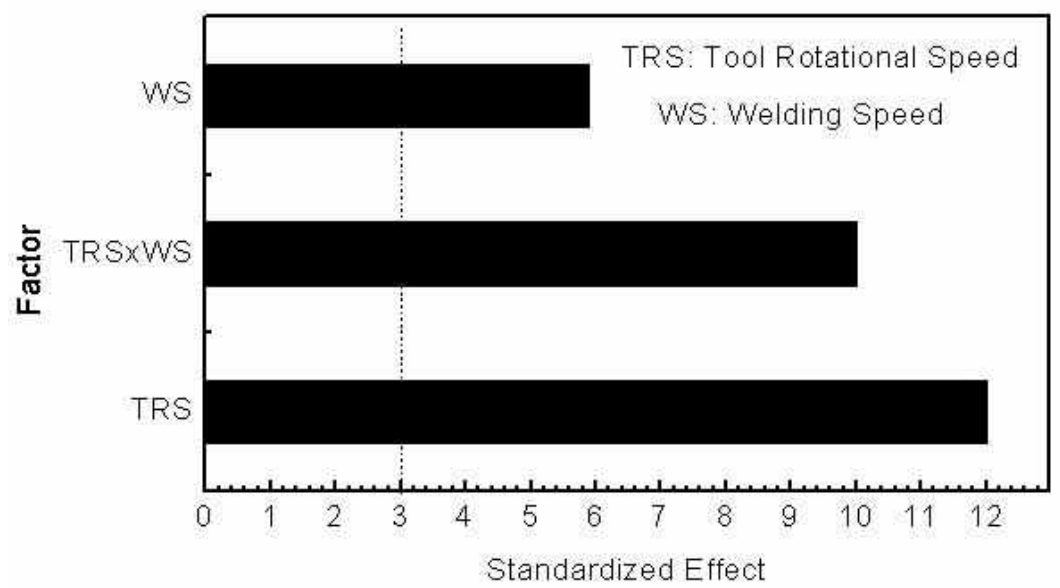

Fig. 11. Standardized Pareto chart for size of Si particulates.

\section{CONCLUSIONS}

1. Modelling of the influence of both tool rotation and welding speeds FSW parameters on both the size of primary $\alpha$-Al grains and the primary Si particulates in the stirred zone (SZ) of welded A356 plates has been carried out using experimental design approach. The developed models were found to be having high accuracies. The equations of primary $\alpha-\mathrm{Al}$ grains and the primary $\mathrm{Si}$ particulates showed accuracies of $94.3 \%$ and $99.2 \%$, respectively.

2. The tool rotation speed has higher effect on the size of $\alpha$-Al grains in comparison with welding speed. The interaction between tool rotation speed and welding 
speed has the lowest statistical and physical significance on the size of $\alpha-\mathrm{Al}$ grains.

3. The tool rotation speed has the most significant influence on the size of $\mathrm{Si}$ particulates, followed by the combination of tool rotation and welding speeds. The welding speed has the lowest significant influence on the size of Si particulates.

\section{REFERENCES}

1. Mishra R. S., Ma Z. Y., "Friction stir welding and processing”, Mater. Sci. Eng., R 50, 2005, pp. 1-78.

2. D. Harris, A.F. Norman, "Properties of friction stir welded joints: a review of the literature", in: Progress Report presented at the 6th PSG Meeting, 17-18 June, 2003.

3. P.M.G.P. Moreira, M.A.V. de Figueiredo, P.M.S.T. de Castro, "Fatigue behavior of FSW and MIG weldments for two aluminum alloys", Theoretical and Applied Fracture Mechanics, 48, 2007, pp. 169-177.

4. Cabello Munoz A., Ruckert G., Huneau B., Sauvage X., Marya S., "Comparison of TIG welded and friction stir welded $\mathrm{Al}-4.5 \mathrm{Mg}-0.26 \mathrm{Sc}$ alloy", J. Mater. Process. Technol., 197, 1-3, 2008, pp. 337-343.

5. Xie G.M., Ma Z.Y., Geng L., Chen R.S., "Microstructural evolution and mechanical properties of friction stir welded $\mathrm{Mg}-\mathrm{Zn}-\mathrm{Y}-\mathrm{Zr}$ alloy", Mater. Sci. Eng. A, 471, 2007, pp. 63-68.

6. Bobby Kannan M., Dietzel W., Zeng R., Zettler R., dos Santos J.F., "A study on the SCC susceptibility of friction stir welded AZ31 Mg sheet", Mater. Sci. Eng. A, 460-461, 2007, pp. 243-250.

7. Sato Y. S., Arkoma P., Kokawa H., Nelson T.W., Steel R. J., "Effect of microstructure on properties of friction stir welded Inconel Alloy 600", Mater. Sci. Eng., A, 477, 1-2, 2008, pp. 250-258.

8. Yu Zhang, Yutaka S. Sato, Hiroyuki Kokawa, Seung Hwan C. Park, Satoshi Hirano, "Microstructural characteristics and mechanical properties of Ti-6Al-4V friction stir welds", Mater. Sci. Eng. A, 485, 1-2, 2008, pp. 448-455.

9. H.S. Park, T. Kimura, T. Murakami, Y. Nagano, K. Nakata, M. Ushio, Mater. Sci. Eng. A, 371, 2004, pp. 160-169.

10. Steuwer A., M.J. Peel, P.J. Withers, "Dissimilar friction stir welds in AA5083AA6082:The effect of process parameters on residual stress", Mater. Sci. Eng. A, 441, 2006, pp. 187-196.

11. Yutaka S. Sato, Seung Hwan C. Park, Masato Michiuchi, Hiroyuki Kokawa, "Constitutional liquation during dissimilar friction stir welding of $\mathrm{Al}$ and $\mathrm{Mg}$ alloys", Scr. Mater., 50, 2004, pp. 1233-1236.

12. Fernandez G.J., Murr L.E., "Characterization of tool wear and weld optimization in the friction-stir welding of cast aluminum $359+20 \% \mathrm{SiC}$ metal-matrix composite", Mater. Characterization, 52, 2004, pp. 65- 75.

13. Cavaliere P., Rossi G.L., Di Sante R., Moretti M., "Thermo-elasticity for the evaluation of fatigue behavior of $7005 / \mathrm{Al}_{2} \mathrm{O}_{3} / 10_{\mathrm{p}}$ metal matrix composite sheets joined by FSW", Int. Journal of Fatigue, 30, 2008, pp. 198-206. 
14. S. R. Ren, Z.Y. Ma and L.Q. Chen, "Effect of welding parameters on tensile properties and fracture behavior of friction stir welded Al-Mg-Si alloy ", Scr. Mater., 56, 2007, pp. 69-72.

15. Kim Y.G., Fujii H., Tsumura T., Komazaki T., Nakata K., Kim Y.G., Fujii H., Tsumura T., Komazaki T., Nakata K., " Effect of welding parameters on microstructure in the stir zone of FSW joints of aluminum die casting alloy", Materials Letters, 60, 2006, pp. 3830-3837.

16. Tomotake Hirata, Taizo Oguri, Hideki Hagino, Tsutomu Tanaka, Sung Wook Chung, Yorinobu Takigawa, Kenji Higashi, "Influence of friction stir welding parameters on grain size and formability in 5083 aluminum alloy", Mater. Sci. Eng. A, 456, 2007, pp. 344-349.

17. Lim S., Kim S., Lee C., Lee C. G., Kim S., "Tensile behavior of friction-stirwelded A356-T6/Al 6061-T651 bi-alloy plate", Metall. Mater. Trans. A, 35, 2004, pp. 2837-2843.

18. Dogulas C. Montgomery, "Design and analysis of experiments", $6^{\text {th }}$ edition, John Wiley \& Sons. Inc., 2005.

19. Mahmoud T. S., Mahmoud F. H., Zakaria H., Khalifa T. A., "Effect of squeezing on porosity and wear behaviour of partially remelted A319/20 vol.-\% SiCp MMCs", Proc. IMechE, Part C: J. Mechanical Engineering Science, 2008, 222(C3), pp. 295-303.

20. Abdel Aziz M., Mahmoud T.S., Abdel Aal A., "Modeling and optimizing of factors affecting erosion-corrosion of AA6063-(TiC/Al2O3) hybrid composites by experimental design method", Materials Science and Engineering: A, Volume 486, Issues 1-2, 15 July 2008, pp. 313-320.

21. Kim Y.G., Fujii H., Tsumura T., Komazaki T., Nakata K., "Three defect types in friction stir welding of aluminum die casting alloy", Mater. Sci. Eng. A, 415, 2006, pp. 250-254.

22. Mahmoud T. S., "Effect of friction stir processing on electrical conductivity and corrosion resistance of AA6063-T6 Al alloy", Proc. IMechE Part C: J. Mechanical Engineering Science, 2008, 222 (C7), pp. 1117-1123. 
إختبار العوامل الخاصة بعلية اللحام بالتقليب الاحتكاكى على منطقة التقليب لسبائك

\section{A356}

فى هذا البحث استخدام اسلوب تصميم التجارب وذلك لامثلة كل من سرعة الدوران و سرعة

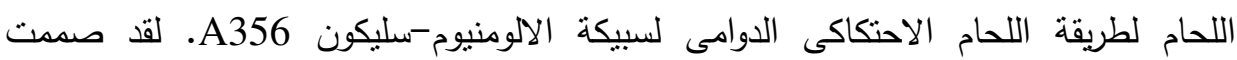

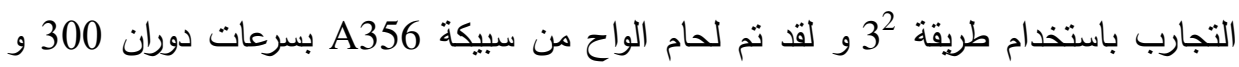

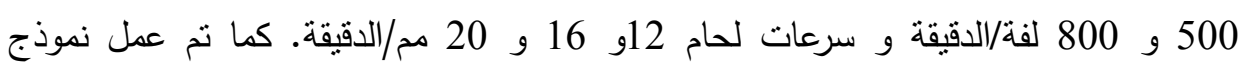
رياضى لحساب حجم حبيبات الالومنيوم و حجم حبيبات السليكون فى منطقة التقليب داخل الوصلات الملحومة. لقد نم نطوير هذا النموذج كدالة فى كل من عاملى سرعة الدوران و سرعة

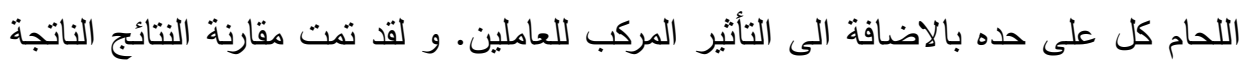

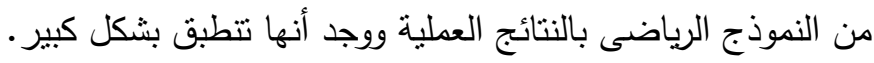

